\title{
Development of a fault simulator for soils under large vertical stress in a centrifuge
}

\author{
Jiro Takemura \\ Associate Professor, Department of Civil and Environmental Engineering, \\ Tokyo Institute of Technology, Tokyo, Japan (Orcid:0000-0002-7460-921X) \\ Chaofan Yao \\ PhD candidate, Department of Civil and Environmental Engineering, \\ Tokyo Institute of Technology, Tokyo, Japan (corresponding author: \\ yaochaofan@hotmail.com) (Orcid:0000-0003-4182-1959)
}

\author{
Osamu Kusakabe \\ Emeritus Professor, Department of Civil and Environmental Engineering, \\ Tokyo Institute of Technology, Tokyo, Japan (Orcid:0000-0003-0852-2199)
}

Severe damages of structures observed in previous earthquakes due to faulting, especially reverse faulting with large discontinuous ground displacement under large earth pressure, have triggered studies on the failure mechanism of structures within fault zone. However, most of centrifuge tests focused on normal faulting due to the lack of apparatus simulating faulting under large earth pressure. In this research study, a fault simulator was designed and manufactured for centrifuge study of buried structures in soils over dip-slip fault, by which a large overburden pressure can be applied to the model soil. The design specifications are: (a) both normal and reverse faulting can be generated, (b) the simulator can function for reverse faulting condition under $50 \mathrm{~g}$ with the surcharge pressure of $500 \mathrm{kPa},(c)$ the maximum offset of $30 \mathrm{~mm}$ with the dip angle of $60^{\circ}$ can be achieved at the bottom of model soil, $(d)$ the front face is transparent to observe the model ground during centrifuge tests. Using the fault simulator, a preliminary test series on buried pipe are conducted. The developed fault simulator shows very promising results with respect to rupture propagation, ground deformation and pipe behaviour.

\author{
Notation \\ Dr relative density \\ $d_{50} \quad$ median particle diameter \\ $e_{\max }$ maximum void ratio \\ $e_{\min }$ minimal void ratio \\ $G_{\text {s }} \quad$ specific gravity of soil particle \\ $H \quad$ height of ground \\ $W \quad$ width of rupture zone (horizontal distance from the \\ fault tip to the rupture top) \\ $\delta b \quad$ bedrock offset \\ $\delta b_{\mathrm{h}} \quad$ horizontal component of bedrock offset \\ $\delta b_{\mathrm{v}} \quad$ vertical component of bedrock offset \\ $\delta v \quad$ vertical displacement of sand \\ $\delta v_{\max }$ maximum vertical displacement of sand at a \\ certain depth \\ $\mu \quad$ mean value of the complimentary error function \\ $\sigma \quad$ standard deviation of the complimentary error function \\ $\Phi(x) \quad$ complimentary error function \\ $\psi \quad$ angle of dilation
}

\section{Introduction}

The behaviour of alluvial deposits subjected to fault displacement in the bedrock is one of the major concerns for almost all structures within a fault zone. An understanding of the fault rupture propagation in the sedimentary soil would assist engineers in siting and designing the critical structures, such as houses, tunnels, bridges and buried pipes, in the regions where soils overlie active or potentially active fault.

Tremendous efforts have been made to study the fault rupture propagation and resultant surface displacement from the case studies. Wells and Coppersmith (1994) complied 421 historical earthquakes and selected 244 earthquakes with reliable source parameters. They produced empirical relationships among magnitude, rupture length, rupture width, rupture area and surface displacement. It could be partly attributed to the complexity of fault rupture propagation phenomena controlled by many factors, such as (i) type of fault movement (reverse, normal or strike slip), (ii) inclination of the fault plane, (iii) amount of displacement on the fault and (iv) geometry and nature of overburden soil. From indicative fault rupture field studies, Bray et al. (1994) showed typical paths of the rupture for three types of fault, suggesting that the characteristics of overburden soil strongly influence the observed fault rupture propagation.

To compensate the shortcoming of the field study, that is, the lack of well-documented field data on the behaviour of overburden soil due to faulting, and study the mechanisms involved in the fault rupture propagation, physical modelling has been performed for several decades. Table 1 summarises 
Table 1. Fault simulators used in previous research studies

\begin{tabular}{|c|c|c|c|c|c|c|}
\hline Author(s) & Fault type & Dip angle: ${ }^{\circ}$ & $\begin{array}{l}\text { Actuating } \\
\text { system }\end{array}$ & g-level & Soil type & Specific features \\
\hline Roth et al. (1981) & $\begin{array}{l}\text { Dip-slip } \\
\quad \text { (reverse) }\end{array}$ & $45^{\circ}$ & Toggle hydraulic & 50 & $\begin{array}{l}\text { Loose sand, dense sand, } \\
\text { remoulded cohesive soil }\end{array}$ & $\begin{array}{l}\text { g-level effect, rate of fault } \\
\text { displacement }\end{array}$ \\
\hline $\begin{array}{l}\text { Cole and Lade (1984) } \\
\text { Lade et al. (1984) }\end{array}$ & $\begin{array}{l}\text { Dip-slip } \\
\text { (both) }\end{array}$ & $\begin{array}{l}30,45,60 \\
75,90\end{array}$ & $\begin{array}{l}\text { Horizontal and } \\
\text { vertical screw } \\
\text { jacks }\end{array}$ & 1 & $\begin{array}{l}\text { Dense sand, loose sand, } \\
\text { mixture of sand and } \\
\text { styrofoam beads }\end{array}$ & $\begin{array}{l}\text { Rupture propagation, } \\
\text { influence zone, multiple } \\
\text { failure surfaces }\end{array}$ \\
\hline $\begin{array}{l}\text { Tani et al. (1994) } \\
\text { Ueta and Tani (1999) }\end{array}$ & $\begin{array}{l}\text { Dip-slip } \\
\text { (reverse) }\end{array}$ & $\begin{array}{r}15,30 \\
45,60 \\
75,90\end{array}$ & Hydraulic & 1 & $\begin{array}{l}\text { Dense silica sand } \\
\left(d_{50}=0.17 \mathrm{~mm}\right. \\
1.3 \mathrm{~mm})\end{array}$ & $\begin{array}{l}\text { Effects of dip angle, soil } \\
\text { depth and particle size }\end{array}$ \\
\hline $\begin{array}{l}\text { Stone and Brown } \\
\text { (1993) } \\
\text { White et al. (1994) }\end{array}$ & $\begin{array}{l}\text { Dip-slip } \\
\text { (both) }\end{array}$ & 90 & Hydraulic & 75,150 & $\begin{array}{l}\text { Silica sand } \\
\qquad\left(d_{50}=0.25 \mathrm{~mm}\right. \\
0.5 \mathrm{~mm} ; \operatorname{Dr} .=90 \%)\end{array}$ & Particle-size effect \\
\hline Miyajima et al. (2003) & $\begin{array}{l}\text { Dip-slip } \\
\quad \text { (reverse) }\end{array}$ & 90 & $\begin{array}{r}\text { Mechanical } \\
\text { (table lift) }\end{array}$ & 1 & $\begin{array}{l}\text { Silica sand }\left(d_{50}=0 \cdot 34\right. \\
\text { Dr. }=20 \%, 80 \%)\end{array}$ & Behaviour of buried pipe \\
\hline $\begin{array}{l}\text { Lee et al. (2003) } \\
\text { Lee and Hamada } \\
\text { (2005) }\end{array}$ & $\begin{array}{l}\text { Dip-slip } \\
\text { (both) }\end{array}$ & $30,45,60$ & $\begin{array}{l}\text { Mechanical } \\
\text { (jack) }\end{array}$ & 1 & $\begin{array}{l}\text { Silica sand } \\
\qquad\left(d_{50}=0.24 \mathrm{~mm} ;\right. \\
\text { Dr. }=59 \pm 4 \%, 83 \pm 4 \%)\end{array}$ & $\begin{array}{l}\text { Surface rupture and } \\
\text { influence zone }\end{array}$ \\
\hline $\begin{array}{l}\text { Lee et al. (2003) } \\
\text { Lee and Hamada } \\
\text { (2005) }\end{array}$ & $\begin{array}{l}\text { Dip-slip } \\
\text { (reverse) }\end{array}$ & 45 & Hydraulic & 30,50 & $\begin{array}{l}\text { Silica sand } \\
\qquad\left(d_{50}=0 \cdot 157 \mathrm{~mm} ;\right. \\
\text { Dr. }=74 \pm 6 \cdot 5 \%)\end{array}$ & $\begin{array}{l}\text { Surface rupture and } \\
\text { influence zone }\end{array}$ \\
\hline $\begin{array}{l}\text { El Nahas et al. (2006) } \\
\text { Anastasopoulos et al. } \\
\text { (2007) }\end{array}$ & $\begin{array}{l}\text { Dip-slip } \\
\text { (both) }\end{array}$ & 60 & Hydraulic & 100,115 & $\begin{array}{l}\text { Silica sand } \\
\qquad\left(d_{50}=0.24 \mathrm{~mm}\right. \\
\text { Dr. }=59 \pm 4 \%)\end{array}$ & $\begin{array}{l}\text { Rupture propagation, } \\
\text { behaviour of raft }\end{array}$ \\
\hline $\begin{array}{l}\text { Ha et al. (2006) } \\
\text { Ha et al.(2008) }\end{array}$ & Strike-slip & 90 & Hydraulic & 150 & Silica sand $\left(d_{50}=0.3 \mathrm{~mm}\right)$ & Behaviour of buried pipe \\
\hline $\begin{array}{l}\text { Lin et al. (2006) } \\
\text { Lin et al. (2007) }\end{array}$ & $\begin{array}{l}\text { Dip-slip } \\
\quad \text { (reverse) }\end{array}$ & 50,60 & $\begin{array}{l}\text { Mechanical } \\
\text { (jack) }\end{array}$ & 1 & Sand $(\operatorname{Dr} .=55 \%)$ & $\begin{array}{l}\text { Ground deformation, } \\
\text { behaviour of tunnel }\end{array}$ \\
\hline $\begin{array}{l}\text { Chang et al. (2013) } \\
\text { Baziar et al. (2014) }\end{array}$ & $\begin{array}{l}\text { Dip-slip } \\
\quad \text { (reverse) }\end{array}$ & 60 & $\begin{array}{l}\text { Mechanical } \\
\text { (jack) }\end{array}$ & $1,40,80$ & Sand $(\mathrm{Dr} .=50 \%, 70 \%)$ & $\begin{array}{l}\text { g-level, rupture propagation, } \\
\text { ground deformation and } \\
\text { behaviour of tunnel }\end{array}$ \\
\hline $\begin{array}{l}\mathrm{Ng} \text { et al. (2012) } \\
\text { Cai and } \mathrm{Ng}(2014)\end{array}$ & $\begin{array}{l}\text { Dip-slip } \\
\text { (normal) }\end{array}$ & 70 & Hydraulic & 100 & Clay $\left(d_{50}=32 \mu \mathrm{m}\right)$ & $\begin{array}{l}\text { Rupture propagation, ground } \\
\text { deformation }\end{array}$ \\
\hline
\end{tabular}

research studies focusing on fault rupture propagation and deformation of overburden soil in earth material using various types of fault simulators. The primary interest on fault using physical modelling in the early 1980 s was mainly related to the identification of influence zone and the shapes and locations of failure surfaces in overburden soil caused by dip-slip faulting. Roth et al. (1981) described early centrifuge modelling of fault propagation through alluvial soils by a fault simulating apparatus for a small centrifuge in Caltech. They suggested that the rate of fault movement may affect the shape and location of failure surfaces. Cole and Lade (1984) and Lade et al. (1984) performed an extensive $1 \mathrm{~g}$ experimental study on the shapes and locations of failure surfaces propagating through dense and loose sand caused by faulting. A simple model was developed for the shape of failure surface using a logarithmical spiral with an angle of $45^{\circ}+\psi / 2$ and $45^{\circ}-\psi / 2$ at the ground surface for normal fault and reverse fault, respectively, where $\psi$ is the angle of dilation.

Tani et al. (1994) and Ueta and Tani (1999) presented relatively large-size model tests with a maximum of $2 \mathrm{~m}$ deep sand layer under $1 \boldsymbol{g}$ in view of examining the deformation characteristics of uncemented quaternary ground caused by dip-slip faults. The experimental system for creating reverse fault movements is similar to that of Cole and Lade (1984). Tani et al. (1994) argued scale effects of quaternary ground deformation observed by model tests of vertical fault. White et al. (1994) also investigated the particle-size effects from centrifuge model tests using trap door system (Stone and Brown, 1993).

Several earthquakes that occurred in Taiwan and Turkey 1999 (Chi-Chi, Kocaeli and Düzce-Bolu) provided plenty of source materials and further motivated studies on this field (Anastasopoulos and Gazetas, 2007; Lin et al., 2001). Lee et al. (2003) and Lee and Hamada (2005) reported experimental studies on the shape and location of the failure surfaces by conducting both $1 \mathrm{~g}$ model and centrifuge model tests on dry silica sand. They found that there is no distinct variation of failure surface with the change of thickness of the model ground. Comparing the measured dilation angle from the failure surfaces in the $1 \mathrm{~g}$ and the centrifuge tests, the mobilised angle of dilation along the failure surface shows an appreciable difference, 
International Journal of Physical Modelling in Geotechnics Volume 20 Issue 3
Development of a fault simulator for soils under large vertical stress in a centrifuge

Takemura, Yao and Kusakabe suggesting the effect of confining pressure. El Nahas et al. (2006) also developed a centrifuge model, which can simulate normal and reverse faults, using a triangle shape soil base block supported by two hydraulic cylinders. Using this centrifuge model tests, Anastasopoulos et al. (2007) discussed fault rupture propagation through sand by carrying out finite-element analysis and validation through the centrifuge experiments.

Lin et al. (2006) preformed $1 \boldsymbol{g}$ tests on reverse fault to investigate the effects of corresponding factors on deformation of overburden soil through a sandbox. Based on the physical tests, they developed numerical models and suggested that a stiffer Young's modulus leads to early rupture propagation, and a larger dilation angle induces wider fault zone. Similar tests were also performed by Chang et al. (2013) and Chang et al. (2015), using a developed fault simulator in a centrifuge. Using the apparatus developed by Lin et al. (2006) and Chang et al. (2013), Lin et al. (2007) and Baziar et al. (2014) explored the behaviour of tunnels parallel to the rupture surface, respectively.

$\mathrm{Ng}$ et al. (2012) and Cai and $\mathrm{Ng}$ (2014) developed an apparatus simulating normal fault deformation in a centrifuge to explore the effect of a pre-existing fracture on rupture propagation and ground deformation in cemented clay, uncemented clay and mixed soil. It was found that a shear mechanism of ground deformation dominated in the uncemented clay, while a bending deformation mechanism was observed at the ground surface in the cemented clay with and without a pre-existing fracture.

A number of accumulated experiences of damage to buried pipe during earthquakes (Dash and Jain, 2008; O'Rourke and Palmer, 1996; Sorensen and Meyer, 2003; Trifunac and Todorovska, 1997) has motivated to study the influence of buried pipe by faulting and to develop effective countermeasures to mitigate the damage. Miyajima et al. (2003) developed a two-section split shear box and conducted $1 \mathrm{~g}$ experiments on behaviour of buried pipe in dry sand due to vertical reverse fault generated by lifting one half of the shear box. They presented the data of bending moment distributions and vertical displacement profile of the buried pipe with two different embedded depths of the pipe and two different relative densities of the sand. Ha et al. (2006) developed a two-section and a three-section split container for centrifuge modelling of ground deformation to simulate faulting. Both containers can be used for studying the influence of faulting on buried pipe. Ha et al. (2008) reported the results of centrifuge model tests using this container on the effect of permanent ground deformation caused by strike-slip faults on buried pipes.

Numbers of physical model tests have contributed understanding the mechanisms of fault rupture propagation, behaviour of geotechnical structures subjected to the ground deformation by the fault and the effects of various factors on them. However, there are still remaining factors which have not been well investigated by physical modelling, for example, the effect of depth of the alluvium overlying the bedrock fault, especially on behaviour of the soils at the large depth under a large overburden pressure.

This paper describes a fault simulator in a centrifuge, by which a large overburden pressure can be applied to the model soil. With the simulator, preliminary tests are performed on buried pipes. The observed fault rupture propagation and ground deformation are presented, and the effects of overburden stress and type of dip-slip faults on the ground deformation pattern as well as behaviour of the buried pipe are discussed.

\section{Development of the fault simulator}

A fault simulator was designed and manufactured at the Tokyo Institute of Technology for centrifuge study of buried structures subjected to dip-slip fault.

\subsection{Conditions considered in the design of container for model ground and simulator}

The specifications and conditions considered in the design of simulator and soil container are $(a)$ the simulator can function under $50 \mathrm{~g}$, (b) displacement and velocity of bedrock can be controlled during centrifuge test, $(c)$ maximum bedrock offset of $30 \mathrm{~mm}$ can be achieved, $(d)$ both normal and reverse faulting can be generated, (e) surcharge pressure of $500 \mathrm{kPa}$ can be applied on the soil surface to create large overburden stress, $(f)$ adequate force is available for generating reverse faulting under the maximum surcharge pressure in a fault simulator, ( $g$ ) large container inner dimension as much as possible, but the whole test system can be housed in a space available in the swing platform, $(h)$ the front face of the container is transparent to observe the model ground during the centrifuge tests.

\subsection{Specifications and details of container for model ground and simulator}

Considering that the space available for the swing platform of the Mark III centrifuge at the Tokyo Institute of Technology is $900 \mathrm{~mm} \times 900 \mathrm{~mm} \times 900 \mathrm{~mm}$, a whole package of fault simulators with dimensions of $800 \mathrm{~mm}$ (long), $600 \mathrm{~mm}$ (wide) and $755 \mathrm{~mm}$ (high) (Figure 1(b)). Specifications of the fault simulator are summarised in Table 2. The upper part of the package is used for a container of model ground (item 11 in Figures 1(c) and 1(d)), which has internal dimensions of $500 \mathrm{~mm}$ (long), $300 \mathrm{~mm}$ (wide) and $400 \mathrm{~mm}$ (high), made of aluminium alloy. The left side wall and base (item 12 in Figures 1(c) and 1(d)) are movable, which are made from an ingot of the alloy to have an accuracy of the shape. Displacement of the movable wall and base is restricted in the 


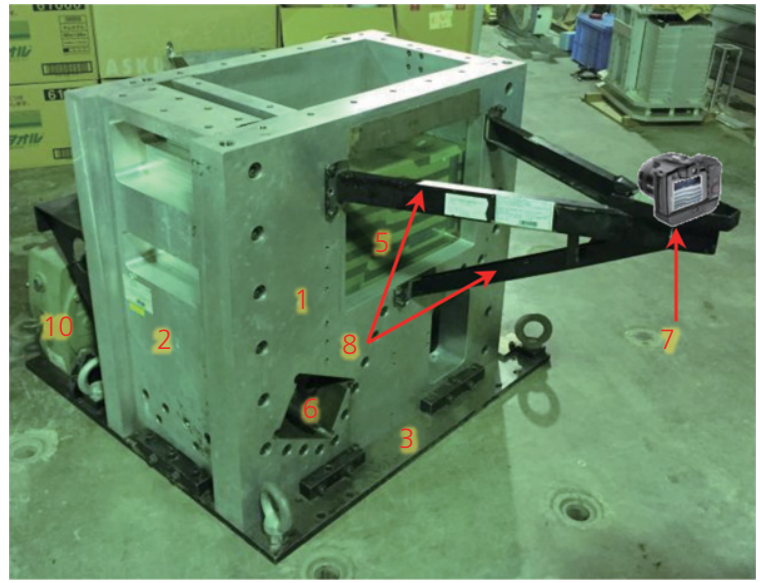

(a)

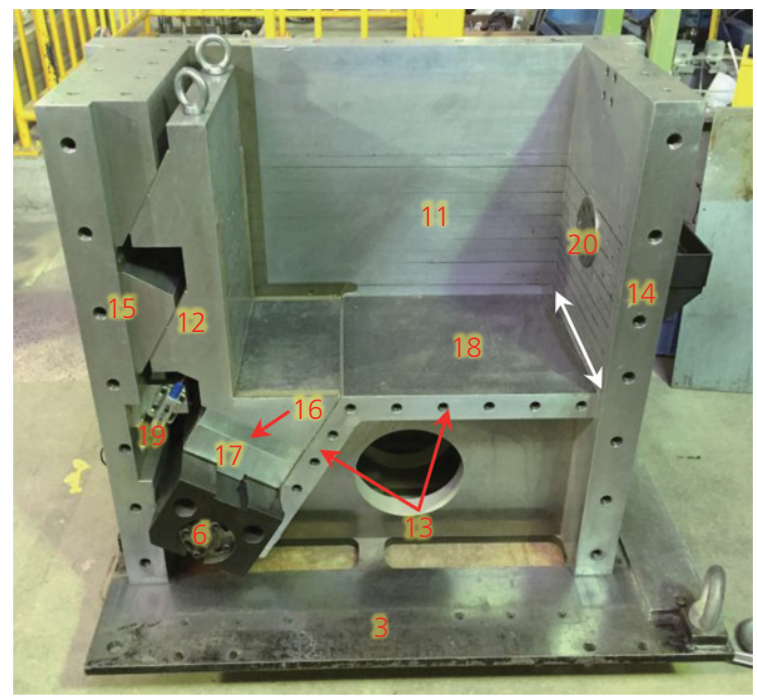

(c)
7. Digital camera

8. Jig for supporting camera

9. Hole for air pressure

10. Worm gear

11. Container for model ground

12. Moveable side wall and base

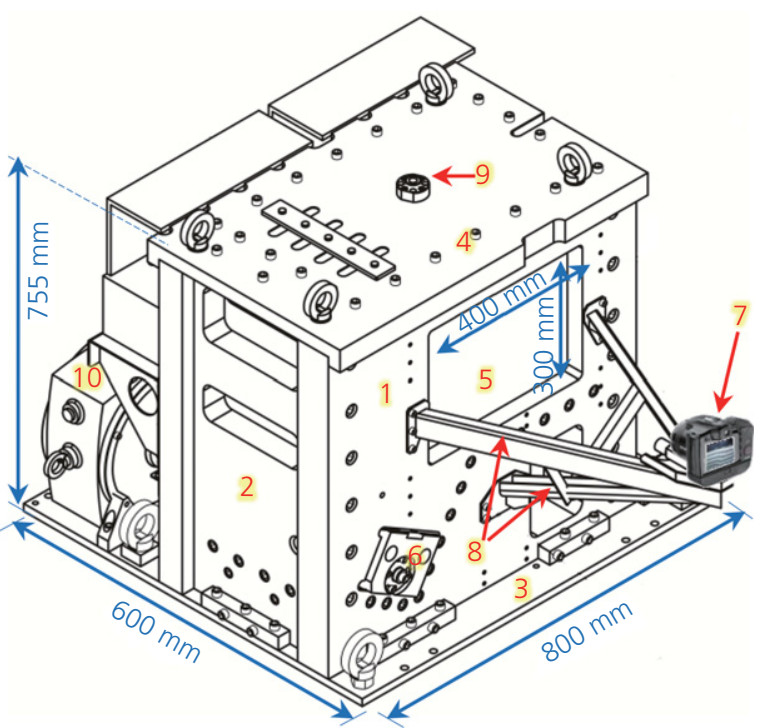

(b)

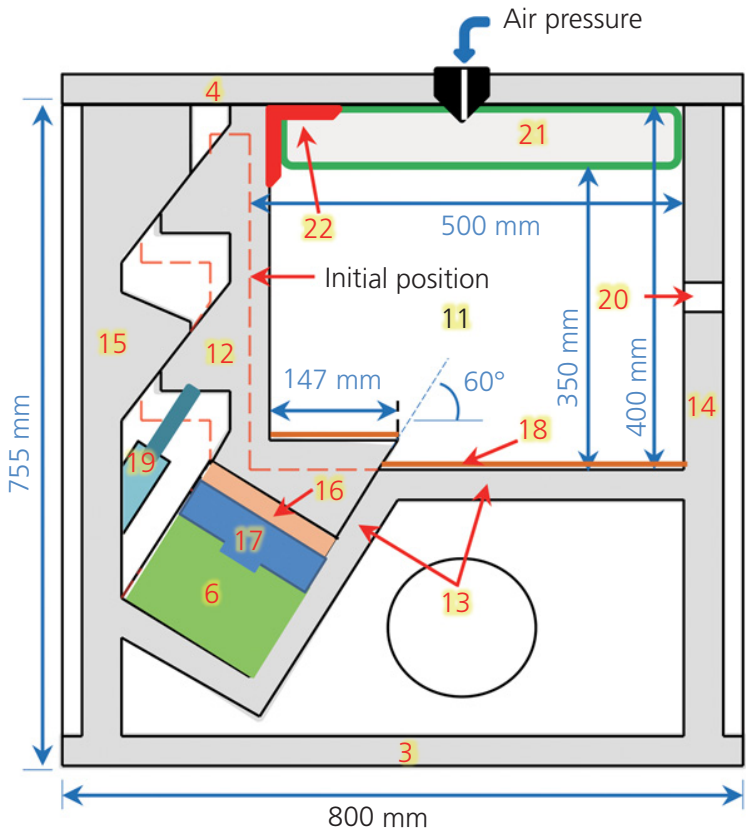

(d)

13. Stationary base and inclined guide 19. LVDT

14. Right side wall 20. Hole for buried pipe and cable

15. Brackets and left outer side wall 21. Rubber bag

16. Spacer block for reverse fault 22. Sliding L-shaped angle

17. Pentagon block

18. Sandpaper

Figure 1. Fault simulator: (a) stereogram; (b) schematic representation of stereogram; (c) photograph of front view; (d) schematic representation of front view

direction of $60^{\circ}$ to the horizontal direction by the inclined guide and the brackets (item 13 in Figures 1(c) and 1(d)). Sandpapers ((item 18 in Figures 1(c) and 1(d))) are lined at the bottom of the model ground container to provide frictional boundary conditions. The lower part of the package houses the thrust mechanism of the fault simulator. At the back of the 
International Journal of Physical Modelling in Geotechnics Volume 20 issue 3
Development of a fault simulator for soils under large vertical stress in a centrifuge

Takemura, Yao and Kusakabe package, it installs an AC servo-motor (item 3 in Figures 2(a) and 2(b)) and 1/50 reduction gear (item 4 in Figures 2(a) and 2(b)) with a maximum torque capacity of $28 \mathrm{~N} \mathrm{~m}$. The torque is amplified by $1 / 50$ worm gear, which is connected to a screw jack (item 5 in Figure 2(b)). The screw jack consists of a rod with normal and reverse screws (items 8 and 9 in

Table 2. Specification of fault simulator

\begin{tabular}{|c|c|}
\hline Overall dimensions & $\begin{array}{l}800 \text { (length) } \times 600 \text { (width) } \times 755 \\
\text { (height) } \mathrm{mm}\end{array}$ \\
\hline $\begin{array}{l}\text { Inside container } \\
\text { dimensions }\end{array}$ & $\begin{array}{l}500 \text { (length) } \times 300 \text { (width) } \times 350 \\
\text { (height) } \mathrm{mm}\end{array}$ \\
\hline Weight of simulator & $636 \mathrm{~kg}$ without soil sample \\
\hline Maximum offset & $30 \mathrm{~mm}$ both for normal and reverse \\
\hline Actuating system & $\begin{array}{l}\text { AC motor }(\text { AC } 1004 \cdot 7 \mathrm{~A})+1 / 50 \text { reduction } \\
\text { gear (torque } 28 \mathrm{~N} \mathrm{~m})+1 / 50 \text { form } \\
\text { gear + inclined block }\left(20^{\circ}\right) \text { driven by screw } \\
\left(20^{\circ}, \mathrm{P} 5 \mathrm{~mm}\right) \text { jack }\end{array}$ \\
\hline $\begin{array}{l}\text { Maximum thrust } \\
\text { force of jack }\end{array}$ & $230 \mathrm{kN}$ \\
\hline Thrust rate of jack & $0-2 \cdot 18 \mathrm{~mm} / \mathrm{min}$ \\
\hline Dip angle & $60^{\circ}$ \\
\hline $\begin{array}{l}\text { Maximum surcharge } \\
\text { pressure }\end{array}$ & $500 \mathrm{kPa}$ \\
\hline
\end{tabular}

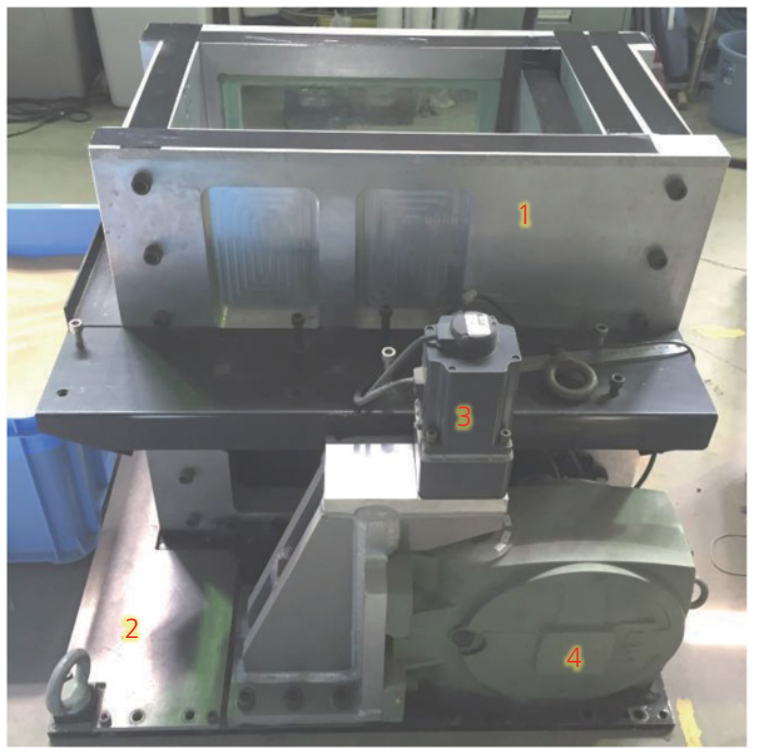

(a)
1. Back plate
5. Screw jack
8. Reverse screw
2. Base plate
6. Pentagon block 9. Normal screw
3. AC servo-mot
4. Worm gear

Figure 2(c)) at the rear and front parts, respectively, two trapezoidal prisms (item 6 in Figure 1 and item 7 in Figure 2(c)), and a pentagon block steel block (item 6 in Figure 2(b)). The trapezoidal blocks are connected to the rear and front screws through nuts. With this combination the two trapezoidal prisms move back and forth in the opposite direction, as shown in Figure 2(c), which actuates the pentagon block and the movable side wall and base upward and downward with a dip angle of $60^{\circ}$, simulating reverse and normal faulting, respectively. With the actuating mechanism explained above, the maximum thrust force of $230 \mathrm{kN}$ can be achieved in relatively small space at the lower part of the package. However, maximum velocity of the fault movement is $2.18 \mathrm{~mm} / \mathrm{min}$. It should be noted that at this velocity the effect of inertia is not modelled.

The maximum displacement of the block imposed by the movement of the trapezoidal prism from the innermost to outermost positions is $30 \mathrm{~mm}$. To impose the maximum relative offset of $30 \mathrm{~mm}$ both for the normal and reverse faulting, a $30 \mathrm{~mm}$ thick spacer (item 16 in Figures 1(c) and 1(d)) is placed on the block and the prism is moved from the outermost to innermost positions for the reverse faulting. At all interfaces between the movable and stationary parts, specific

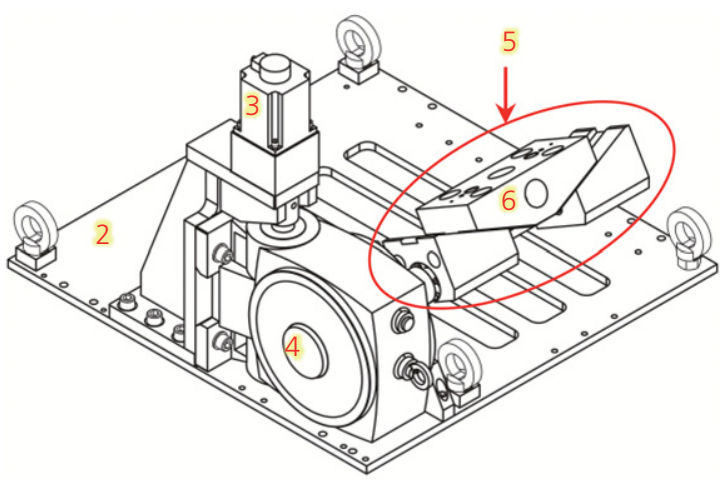

(b)

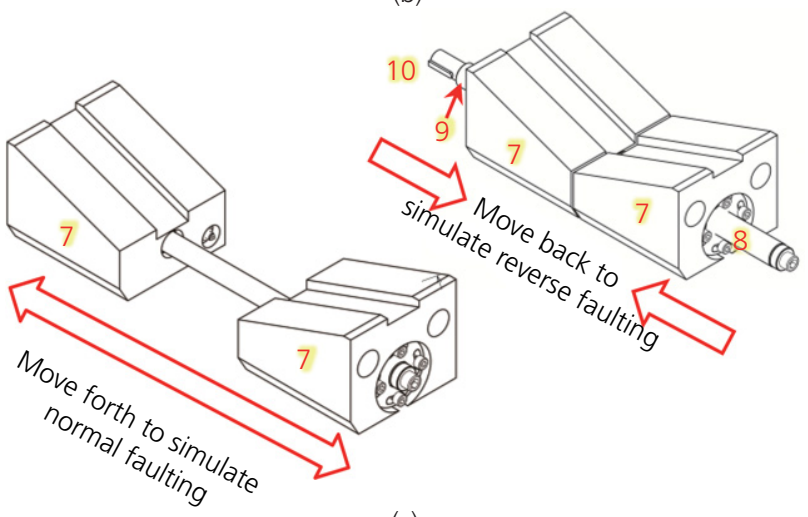

(c)

Figure 2. Actuating system of the fault simulator: (a) back view of the fault simulator; (b) actuating system; (c) screw jack 
International Journal of Physical Modelling in Geotechnics Volume 20 Issue 3
Development of a fault simulator for soils under large vertical stress in a centrifuge

Takemura, Yao and Kusakabe
Teflon thin plates (LFP-25100, 2.5 mm thick, Oiles Corp., Japan) are provided to reduce the friction at the interface. These thin plates also function as a gap filler to avoid the intrusion of sand particles into the gap.

A cubic-shaped rubber bag (item 21 in Figure 1(d)) can be placed on the top of the model ground to apply the maximum surcharge pressure of $500 \mathrm{kPa}$. To support the pressure of the rubber bag, a grid made of aluminium is fixed on the package. A sliding L-shaped steel angle (item 22 in Figure 1(d)) is attached to the grid at the top corner of the movable wall side to prevent the puncture of the bag during the faulting. The front plate of the package has a rectangular glass window (item 5 in Figure 1(a)) of $400 \mathrm{~mm}$ wide, $300 \mathrm{~mm}$ high and $40 \mathrm{~mm}$ thick, through which the occurrence of the fault can be viewed. The whole package has a mass of $627 \mathrm{~kg}$ without a soil model.

When the test is conducted under a centrifugal acceleration of $50 \mathrm{~g}$, the fault simulator typically simulates an event of faulting with a relative displacement of $1.5 \mathrm{~m}$ propagating through the sand layer of 10-18 m depth. When the surcharge of $500 \mathrm{kPa}$ is applied for the soil with maximum depth, the vertical stress of $800 \mathrm{kPa}$ at the bottom of the sand layer can be achieved, which is equivalent to the stress level that a $80 \mathrm{~m}$ deep saturated dense sand layer might experience.

A digital camera (item 7 in Figures 1(a) and 1(b)) in front of observational window supported by jigs (item 8 in Figures 1(a) and 1(b)) to record the digital images during faulting. The digital image is used for data analysis of rupture propagation and ground deformation using particle image velocimetry (PIV) processing (White et al., 2003). For the purpose of the study of buried pipe subjected to faulting, both side walls of the model container have a circular hole (item 20 in Figures 1(a) and 1(b)) of $40 \mathrm{~mm}$ diameter to place a model buried pipe with either free or fixed conditions at the ends of the pipe.

\section{Preliminary tests on buried pipe subjected to faulting in sand}

\subsection{Model preparation and test procedures}

Using the fault simulator, a primary test series was performed on sand with buried steel pipe. All tests were performed under $50 \mathrm{~g}$ condition. Hereafter, all data will be reported as prototype scale unless otherwise stated.

Three test cases were conducted as shown in Figure 3, namely case RS (reverse faulting and shallow buried pipe), case RD (reverse faulting and deep buried pipe) and case NS (normal faulting and shallow buried pipe). Dry Toyoura sand $\left(G_{\mathrm{s}}=2.65, \quad d_{50}=0.19 \mathrm{~mm}, \quad e_{\max }=0.973, \quad e_{\min }=0.609\right.$, Dr. $=80 \%$ ) was used to make the model ground in all cases. The test conditions of each case are listed in Table 3. The heights of model ground were $11 \cdot 1,15 \cdot 7$ and $11.45 \mathrm{~m}$ in cases RS, RD and NS with pipe buried depths of $2 \cdot 1,6 \cdot 7$ and $2.45 \mathrm{~m}$, respectively. The surcharge pressure on the ground surface in case RD was $490 \mathrm{kPa}$, which corresponded to $31.2 \mathrm{~m}$ height of the soil. The coordinate system is illustrated in Figure 3(a), the origin of which is located in the centre of the base.

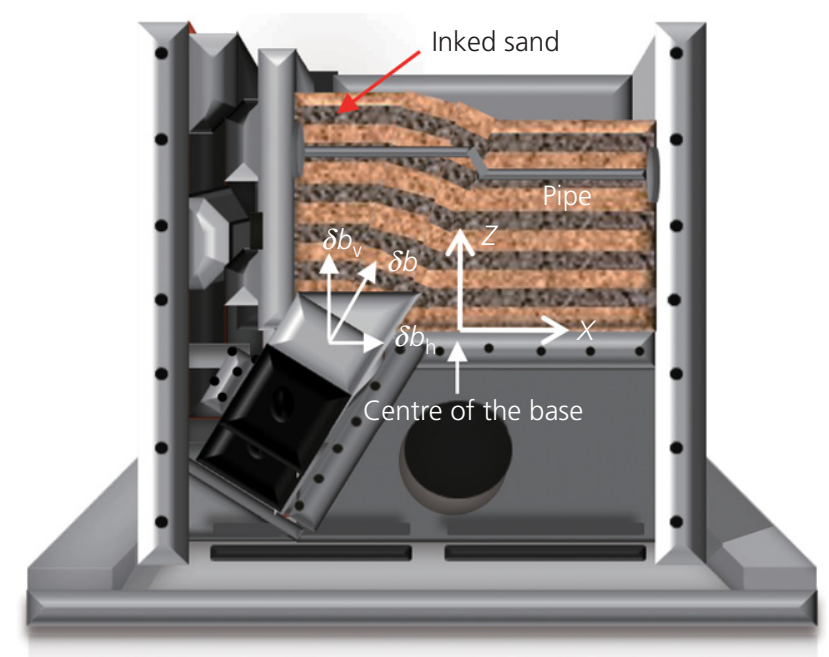

(a)

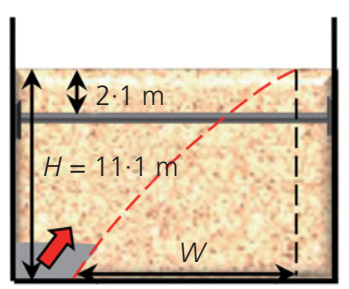

(b)
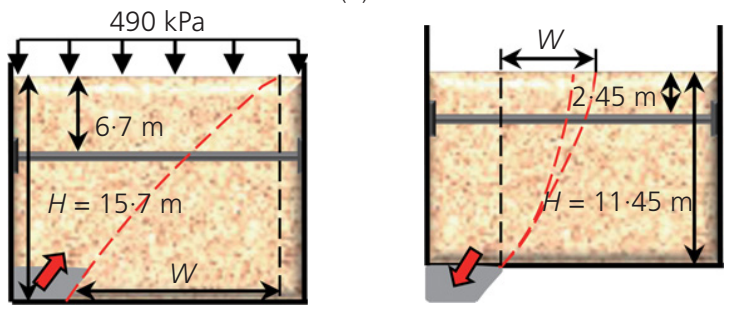

(c)

Figure 3. Test set-ups: (a) schematic representation of all cases; (b) case RS; (c) case RD; (d) case NS 
International Journal of Physical Modelling in Geotechnics Volume 20 Issue 3
Development of a fault simulator for soils under large vertical stress in a centrifuge

Takemura, Yao and Kusakabe
Table 3. Test cases (in prototype scale)

\begin{tabular}{llccr}
$\begin{array}{l}\text { Test } \\
\text { cases }\end{array}$ & Fault type & $\begin{array}{c}\text { Ground } \\
\text { thickness: } \\
\mathbf{m}\end{array}$ & $\begin{array}{c}\text { Buried } \\
\text { depth } \\
\text { of pipe: } \mathbf{m}\end{array}$ & $\begin{array}{r}\text { Surcharge } \\
\text { pressure: } \\
\text { kPa }\end{array}$ \\
\hline RS & Revere fault & $11 \cdot 1$ & $2 \cdot 1$ & 0 \\
RD & Reverse fault & $15 \cdot 7$ & $6 \cdot 7$ & 490 \\
NS & Normal fault & 11.45 & $2 \cdot 45$ & 0 \\
\hline
\end{tabular}

The model pipe used in the test is made of stainless steel with outer diameter of $15 \mathrm{~mm}$ and thickness of $0.5 \mathrm{~mm}$ in model scale, which is equivalent to $750 \mathrm{~mm}$ diameter and $25 \mathrm{~mm}$ thick pipe in prototype, as shown in Figure 4. The pipe has a bending

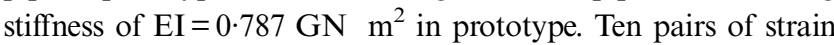
gauges are attached to the inner top and bottom surfaces of the pipe with $40 \mathrm{~mm}$ (in model scale) interval to measure the bending strain of the pipe. The model pipe has a circular fringe at the right end, with which the pipe is rigidly fixed to the side wall. In addition, a solid circular bar with a fringe is inserted on the left end of the pipe. The left fringe is attached to the left wall to create a slider. The reserved space between the left fringe and pipe is about $20 \mathrm{~mm}$, which is larger than the horizontal component of the maximum bedrock offset of $15 \mathrm{~mm}$, to avoid the contact of the left fringe and the pipe. Therefore with this slider no extra axial force is induced to the pipe due to faulting. Therefore it is considered that deflection of the pipe is mainly due to the force caused by the vertical relative movement between the pipe and soil in this model.

Typical test procedures are as follows: (i) fix a model buried pipe to the right side wall; (ii) pour dry Toyoura sand into the container by air pluviation method with a target relative density of $80 \%$; (iii) inked Toyoura sand is poured adjacent to the front window to create alternate layers with $20 \mathrm{~mm}$ thick (in model scale) each for clear identification of the failure surface in the front view; (iv) for case RD, place the rubber bag on the surface of the model sand layer, and feed the air pressure to it after bolting the top grid onto the container; (v) mount the completed model on the swing platform ready for centrifugal acceleration; (vi) having reached $50 \mathrm{~g}$ acceleration, activate the fault simulator by the speed of $2.18 \mathrm{~mm} / \mathrm{min}$ (in model scale) to the maximum offset of $\delta b=30 \mathrm{~mm}$ (in model scale); (vii) during faulting, strain data and digital images are recorded with every bedrock offset increment of $1 \mathrm{~mm}$ (in model scale).

\subsection{Test results and discussion}

\subsubsection{Propagation of fault rupture in sand}

In-flight photos captured during faulting in each case are shown in Figure 5, and the rupture propagations are summarised in Figure 6 with the rupture surface number.

In case RS, the ground discontinuity appeared at the lower part of the ground when $\delta b=0.5 \mathrm{~m}$ (Figure 5(a)). The rupture (RS1) propagated to the middle layer of the ground after $0 \cdot 25 \mathrm{~m}$ more bedrock offset, and it outcropped on the ground surface at $\delta b=0.9 \mathrm{~m}$. With increasing of bedrock offset, another rupture (RS2) above RS1 gradually developed from fault tip to the middle layer of the ground. It may outcrop on the ground surface with further bedrock offset.

In case $\mathrm{RD}$, the ground discontinuity only induced near the fault tip at the base when $\delta b=0.5 \mathrm{~m}$ (Figure $5(\mathrm{~b})$ ). The first rupture (RD1) propagated to the middle of the ground and stopped after bedrock offset reached $1.0 \mathrm{~m}$, and a secondary rupture (RD2) on the hanging-wall side of rupture RD1 initiated. Another discontinuity induced in the upper soil when $\delta b=1.25 \mathrm{~m}$. Then, its lower end developed to connect with the rupture RD2, and its upper end propagated to the ground surface.

For case NS, an initial rupture (NS1) initiated almost vertically at the bottom of the ground with $\delta b=0.25 \mathrm{~m}$ (Figure 5(c)), and it stopped at the lower part of the soil. With $0.2 \mathrm{~m}$ more bedrock offset, another rupture (NS2) on the foot-wall side of NS1 quickly propagated to the ground surface. When bedrock offset reached $0.75 \mathrm{~m}$, the third rupture (NS3) appeared on further foot-wall side of rupture NS2.

The reverse faulting had a wider fault zone than that of normal faulting. It is associated with passive and active soil

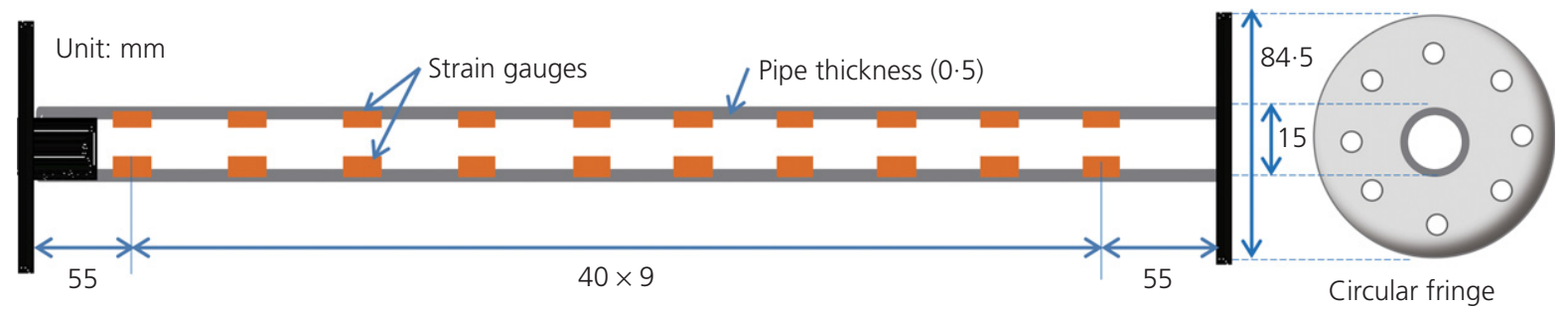

Figure 4. Schematic representation of the model pipe (in model scale) 
Development of a fault simulator for soils under large vertical stress in a centrifuge

Takemura, Yao and Kusakabe
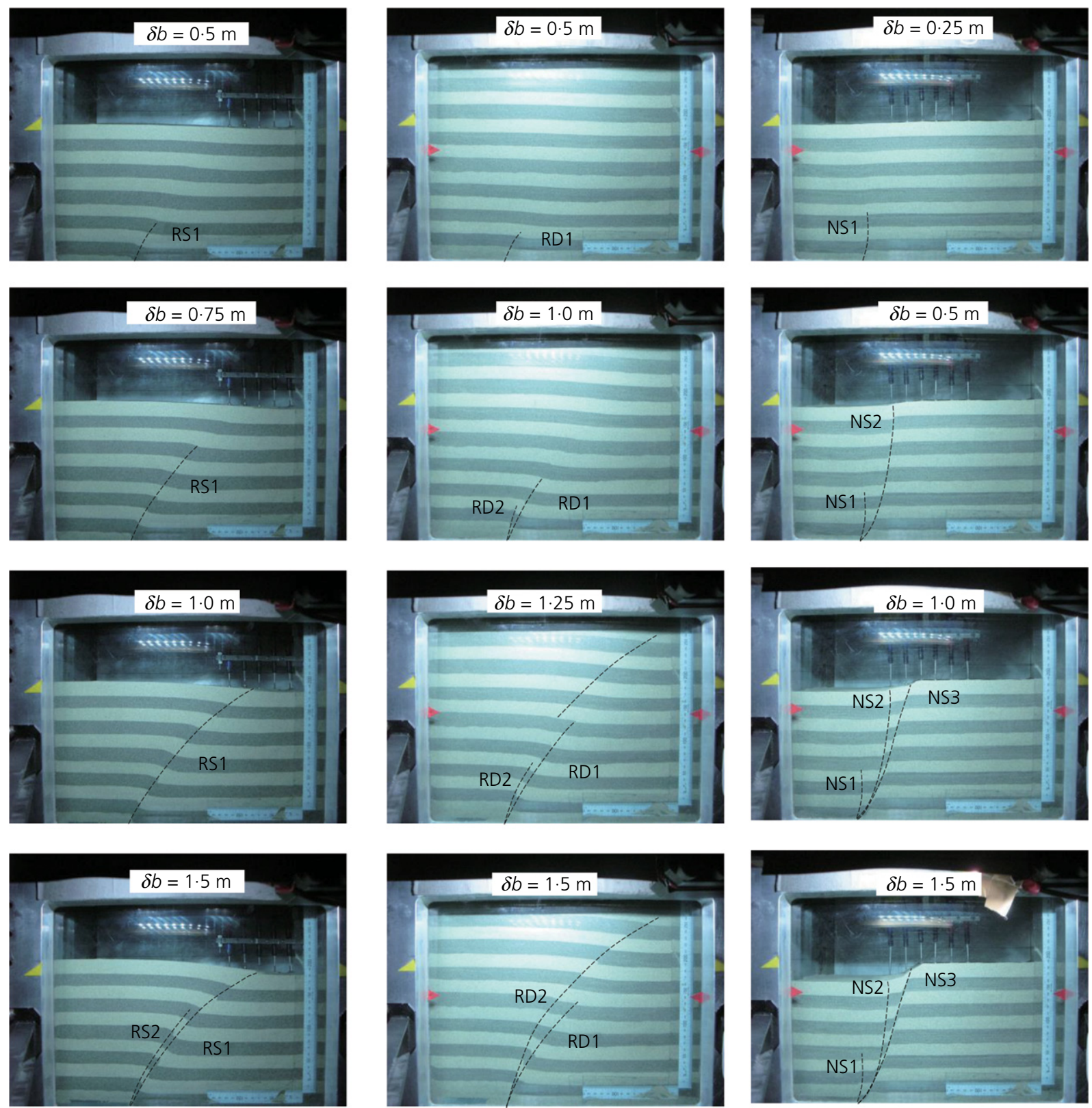

(a)

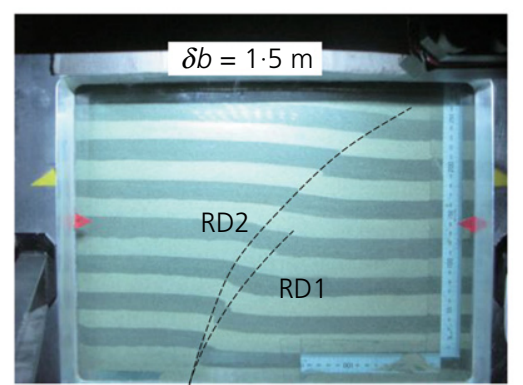

(b)

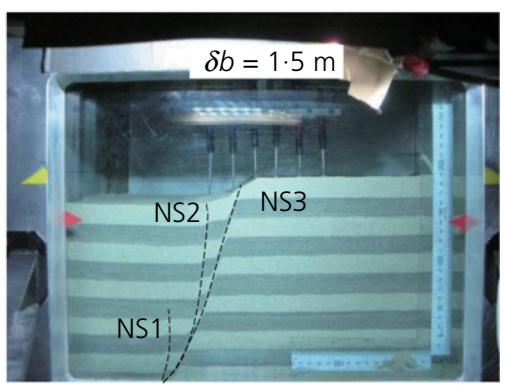

(c)

Figure 5. In-fight photographs captured during faulting: (a) case RS; (b) case RD; (c) case NS

conditions, which are loading and unloading, respectively. The widths of the rupture zone ( $W$, the horizontal distance from the fault tip to the major rupture top or surface rupture, as illustrated in Figure 3(d)) were 10.4 and $3.7 \mathrm{~m}$ for cases RS and NS, corresponding to normalised values $(W / H)$ of 0.94 and $0 \cdot 32$, respectively. The result of case RS agreed with $1 \mathrm{~g}$ test result of Cole and Lade (1984) that $W / H$ was 0.98 for dense sand with a dip angle of $60^{\circ}$. For normal faulting, the
$W / H$ value in case NS was in good agreement with values of $0 \cdot 3-0.4$ and $0 \cdot 3-0.5$ observed in normal faulting tests performed by Lee and Hamada (2005) and Chu et al. (2013), respectively. Besides, the rupture propagation rate was faster in normal faulting than that in reverse faulting, as the observed uplifting ratios $\left(\delta b_{\mathrm{v}} / H\right)$ for outcropping on ground surface were 3.0 and $6.9 \%$ for cases NS and RS. These values were smaller than those observed by Bransby et al. (2008a) and 


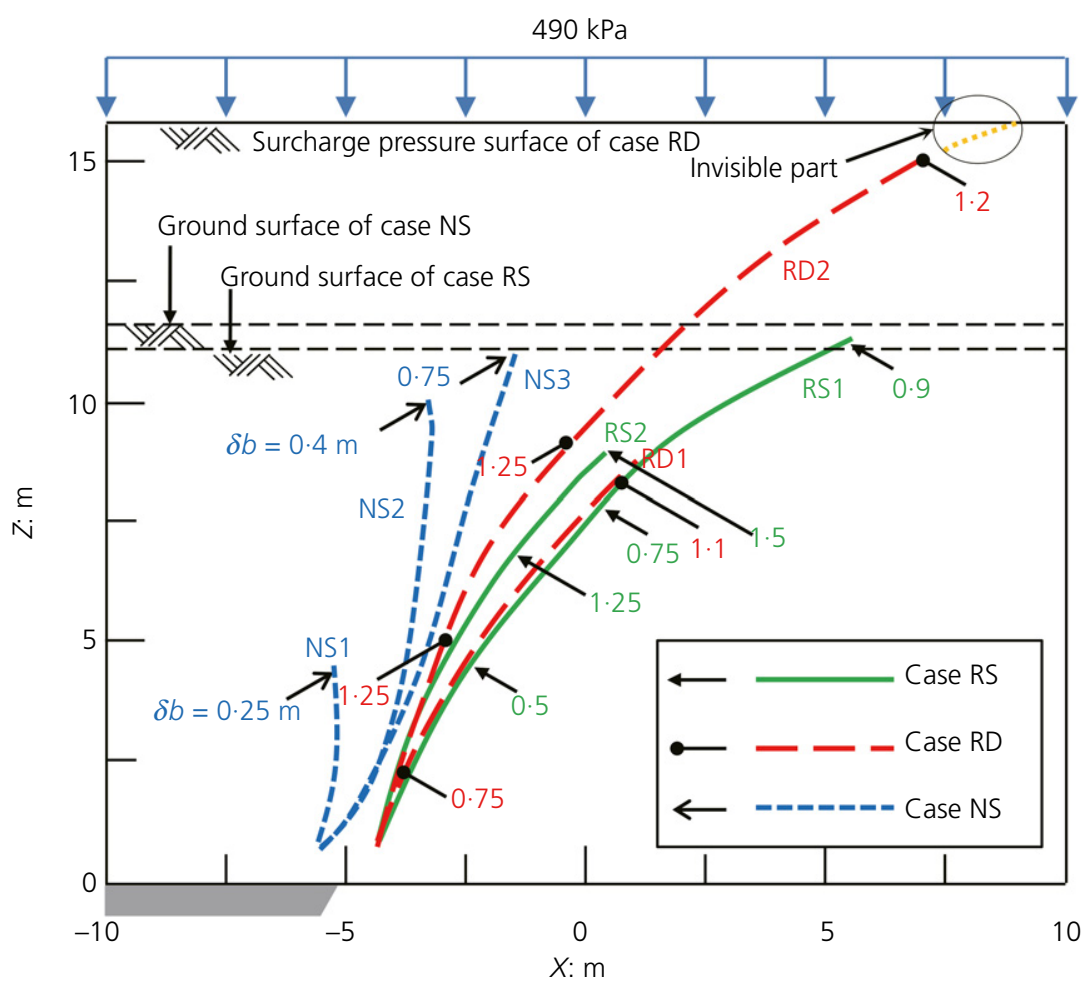

Figure 6. Comparison of rupture propagations of all cases at $\delta b=1.5 \mathrm{~m}$

Bransby et al. (2008b) in their centrifuge tests with a dip angle of $60^{\circ}$, which were 3.2 and $10 \%$ for normal and reverse faulting, respectively. The slower propagation was due to the loose sand $($ Dr. $=60 \%)$ used both in tests of Bransby et al. (2008a) and Bransby et al. (2008b). It is known that lower relative density of sand corresponds to smaller Young's modulus, and the smaller Young's modulus leads to slower propagation (Lin et al., 2006). The faster propagation in normal faulting than that in reverse faulting is due to different stress condition in each case. For the normal faulting, the soil is horizontally extended, while for the reverse faulting the soil is compressed. The stress of the soil for the normal fault is relatively small and close to active condition compared with those for the reverse fault, which have a large stress increase in passive condition. It indicates that soils for the normal fault have smaller failure strain than those for the reverse fault. As a result, soils for the normal fault require smaller relative movement to create a shear band than those for the reverse fault.

As can be seen in Figure 6, RS1 had a lower trace than RD1, and also for RS2 than RD2. It suggested that ruptures in shallower case experienced a smaller propagation direction angle to the $X$ axis. The lower rupture trace in case RS resulted in a wider fault zone, as the normalised widths of fault zone
$(W / H)$ was 0.94 and $0.89(H=15.7 \mathrm{~m})$ at $\delta b=1.5 \mathrm{~m}$ for cases RS and RD, respectively. According to Cole and Lade (1984), the rupture propagation direction is controlled by the angle of dilation. It is known that increasing stress level in soil reduces the angle of dilation, so the smaller angle of dilation in case RD leads to ruptures curved less towards the $X$ axis than those in case RD. Besides, the uplifting ratios $\left(\delta b_{\mathrm{v}} / H\right)$ for outcropping on the ground surface were $7 \cdot 0$ and $6 \cdot 6 \%(H=15 \cdot 7 \mathrm{~m})$ for cases RS and RD (Figure 6). The faster propagation in case $\mathrm{RD}$ is also due to its larger stress level. Since larger stress in sand leads to greater Young's modulus, and greater Young's modulus results in faster propagation (Lin et al., 2006).

\subsubsection{Vertical displacements of the ground due to faulting}

For the case of dip-slip fault with a relatively steep dip angle, like the condition of the test $\left(60^{\circ}\right)$, the vertical differential movement is one of the most critical concerns for the structures constructed in or on the ground. The displacements of the ground induced by the model fault offset were measured by PIV technique (White et al., 2003), based on the in-flight photos captured by the digital camera. Patch size adopted in the PIV analysis was 64 pixels, equivalent to $9.03 \mathrm{~mm}$ in prototype scale. It 
International Journal of Physical Modelling in Geotechnics Volume 20 Issue 3
Development of a fault simulator for soils under large vertical stress in a centrifuge

Takemura, Yao and Kusakabe
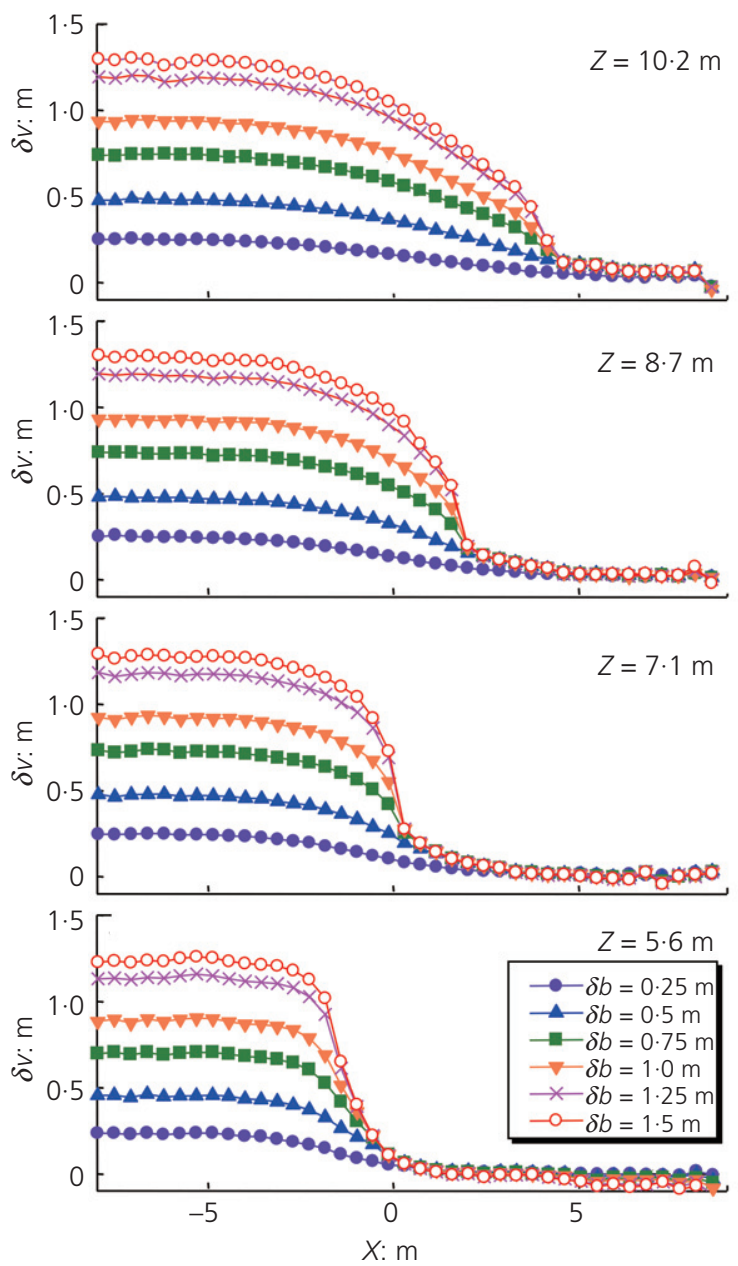

(a)
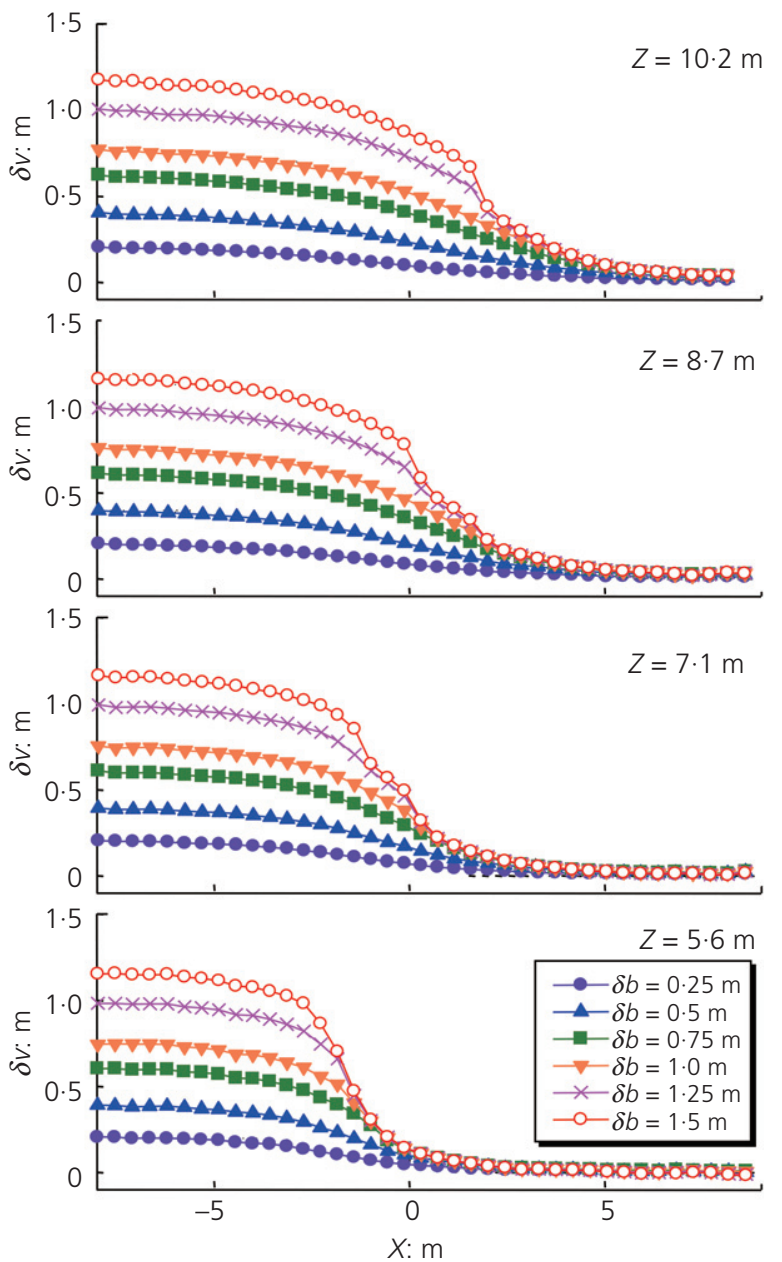

(b)

Figure 7. Vertical displacement profiles at different depths in reverse faulting: (a) case RS; (b) case RD

should be noted that discontinuous deformation might be underestimated due to this relative large patch size.

Vertical displacement profiles at different depths from the bedrock in each case are plotted in Figures 7 and 8. As shown in Figure 7(a), sand on the hanging wall uplifted with the increasing of bedrock offset in case RS, while sand on the footwall had tiny displacements. With further bedrock offsets, a scarp gradually formed at each sand layer. The scarp was steeper in deeper sand layers corresponded to narrower shear zone width. Figure 7(b) presents a similar process of vertical displacement development in case RD. In normal faulting (Figure 8), sand on the hanging wall moved downward with bedrock offset, while the sand on the foot wall had very small vertical displacements. Clear discontinuities were observed when the bedrock offset reached $0.5 \mathrm{~m}$, and they became sharper with larger bedrock offset.
A more intuitive comparison of vertical displacements in all cases is shown in Figure 9. The vertical displacements are normalised by the vertical component of bedrock offset. The vertical displacement was more continuous for the reverse faults than the normal fault, and also for case RD than case RS. The maximum normalised vertical displacements were about 1.0 in both cases RS and NS. However, the maximum value was about 0.85 in case RD. It suggests that the ground movement was prevented by the rubber bag on the ground surface in case RD. The purpose of the air pressure on the ground surface is to break the limitation of height of fault simulator. Compared with the method by increasing test $\boldsymbol{g}$-level or by using the thicker sand layer on the top to provide the same overburden pressure, the above results indicate that soil displacement is underestimated when using air pressure to replace the deep overburden sand layer. However, the underestimation of soil displacement could be evaluated, which is about $15 \%$ in 
Development of a fault simulator for soils under large vertical stress in a centrifuge

Takemura, Yao and Kusakabe
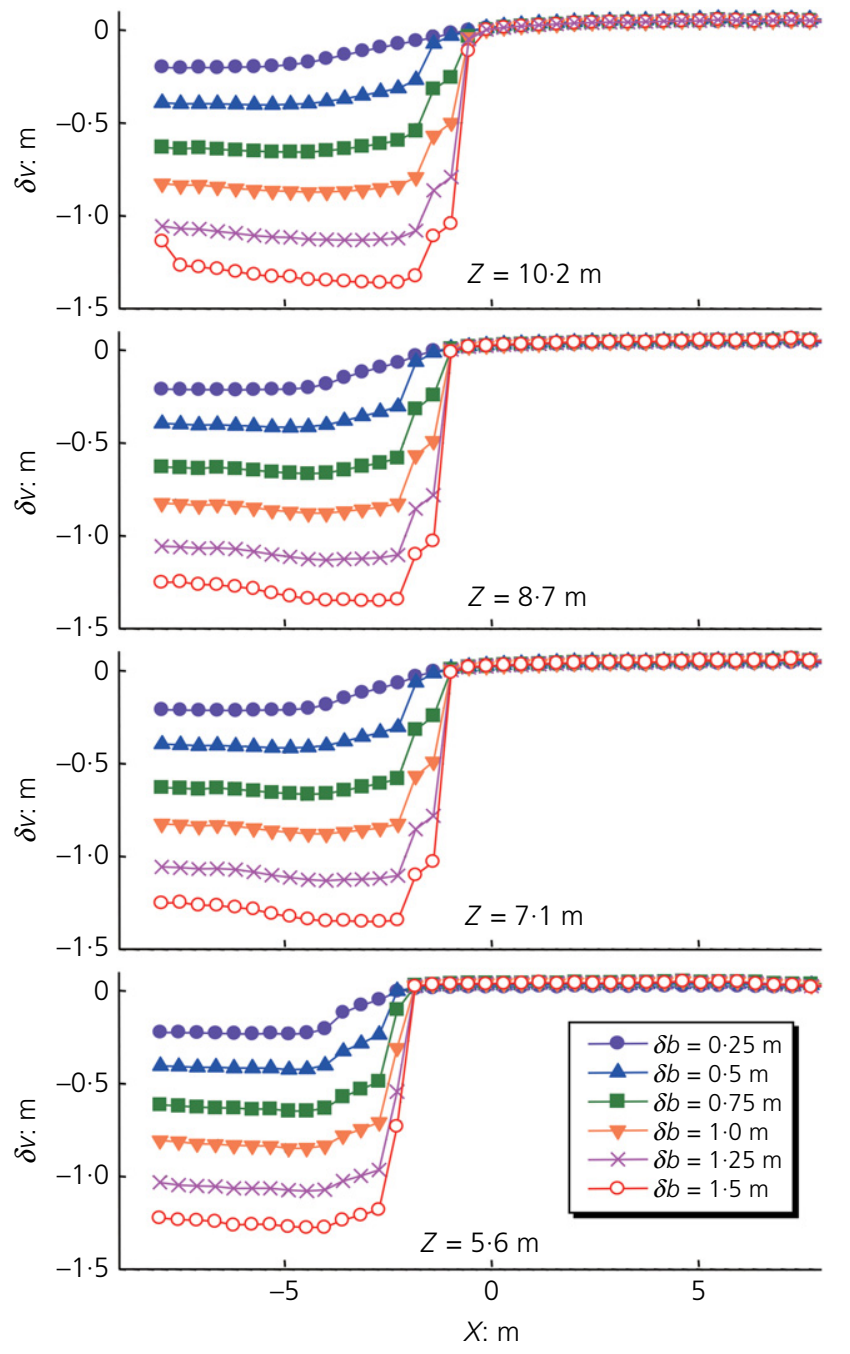

Figure 8. Vertical displacement profiles at different depths in case NS

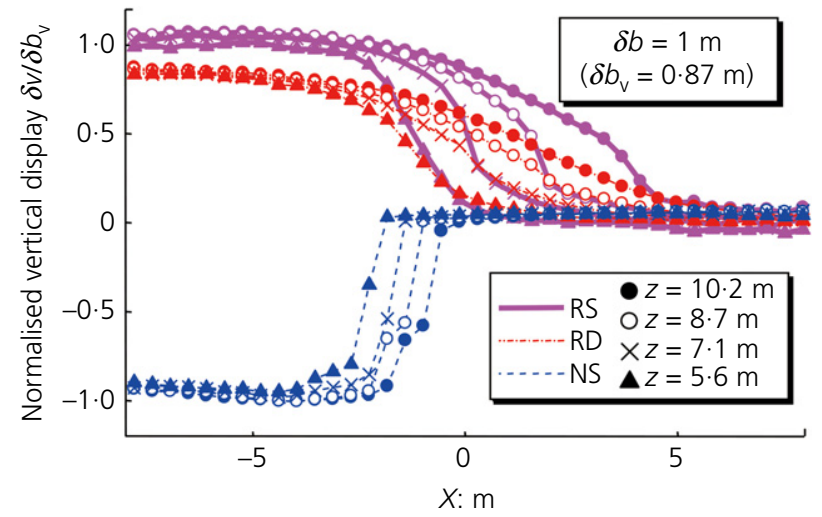

Figure 9. Vertical displacements profiles normalised by $\delta b_{v}$ this test, and it should be considered while interpreting the test results. Although the method by increasing test $\boldsymbol{g}$-level or by using the thicker sand layer on the top to provide the same overburden pressure could simulate relative true soil displacements, it also has some limitations. Different $\boldsymbol{g}$-levels will lead to different scale of the pipe, and the height of the ground is limited by the height of the fault simulator.

To understand the ground movement in a simple way, a complimentary error function (Equation 1, Figure 10(a)) was adopted to approximate the vertical displacements normalised by the maximum value, $\delta v / \delta v_{\max }$ (Takemura et al., 2010). The complimentary error function was initially applied by Roboski and Finno (2006) to fit ground movements parallel to deep excavations in clay. Cai and $\mathrm{Ng}$ (2013) also used this function to estimate the deformation profile of clay induced by normal faulting. As can be seen in Figure 10(a), the observed data can be approximated by complimentary error function. The double value of standard deviation $(2 \sigma)$ can be considered as one of the indices representing the width of steep differential displacement zone. To calculate the value of $2 \sigma$, the two points $\left(x_{1}\right.$, $0 \cdot 84)$ and $\left(x_{2}, 0 \cdot 16\right)$ should be first found from the test data, and then $2 \sigma$ can be determined by value of $x_{2}-x_{1}$. Figure 10(b) compares the normalised vertical displacement profiles and the evaluated ones by Equation 1 at different depths when $\delta b=1.0 \mathrm{~m}$ in case RS. It suggests that the evaluated vertical displacement profiles agree with the measured values. The variations of $2 \sigma \mathrm{s}$ deduced from the normalised profile are compared at $\delta b=0.5$ and $1.5 \mathrm{~m}$ in Figure 10(c). The width of differential displacements zone at the same bedrock offset was larger in reserve faulting than that in normal faulting, and also for case RD than case RS. It suggests that more bedrock offsets are needed to induce a clear discontinuity in deeper case of reverse faulting. Besides, the widths in all cases were getting larger from the deep depth to a shallow one, and they became narrower with the bedrock offset increased. It demonstrates that clear discontinuity gradually developed along rupture surface with larger bedrock offset. It should be pointed out that this function may not well describe the vertical displacement profiles with large discontinuity. However, even in large discontinuity, the $2 \sigma$ can provide a quantitative understanding of width of differential displacement zone.

1. $\phi(x)=1-\frac{1}{\sqrt{2 \pi \sigma}} \int_{-\infty}^{x}\left[\exp \left(-\frac{(x-\mu)^{2}}{2 \sigma^{2}}\right)\right] \mathrm{d} x$

\subsubsection{Behaviour of buried pipes}

Figure 11 shows the bending strains measured by the strain gauges at $\delta b=1.0 \mathrm{~m}$. For case RD, large sharp peaks of 


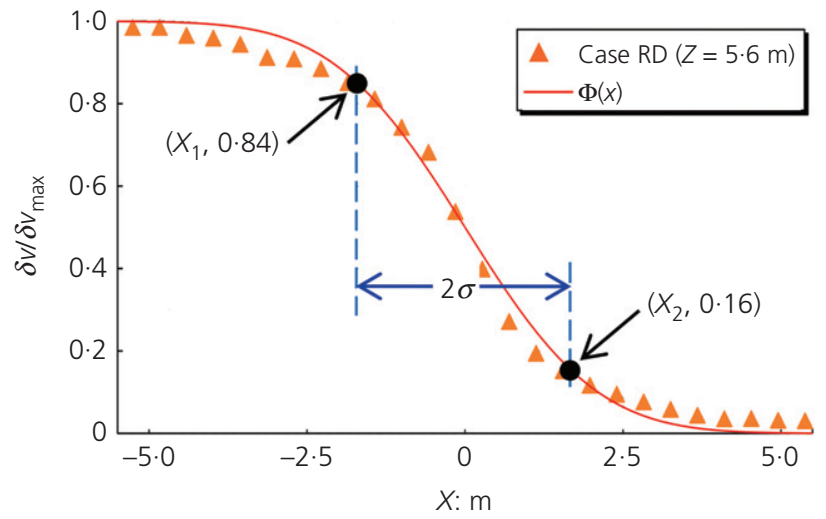

(a)

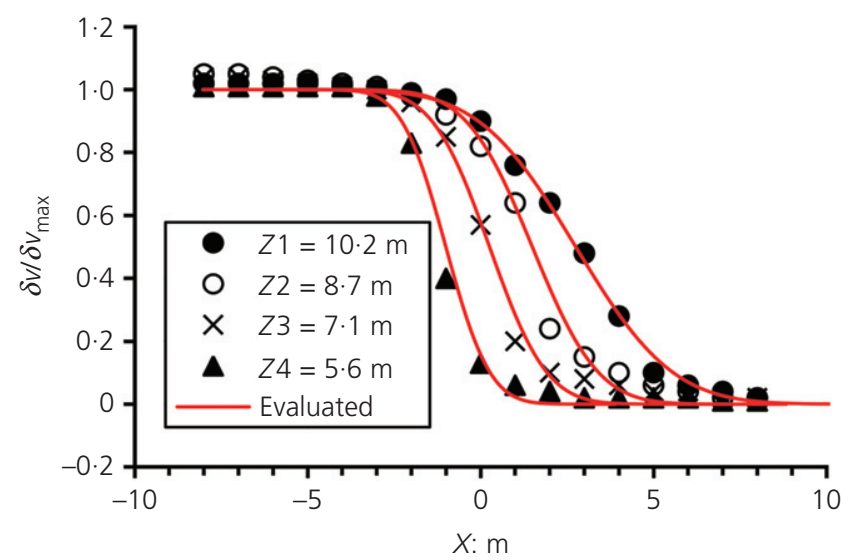

(b)

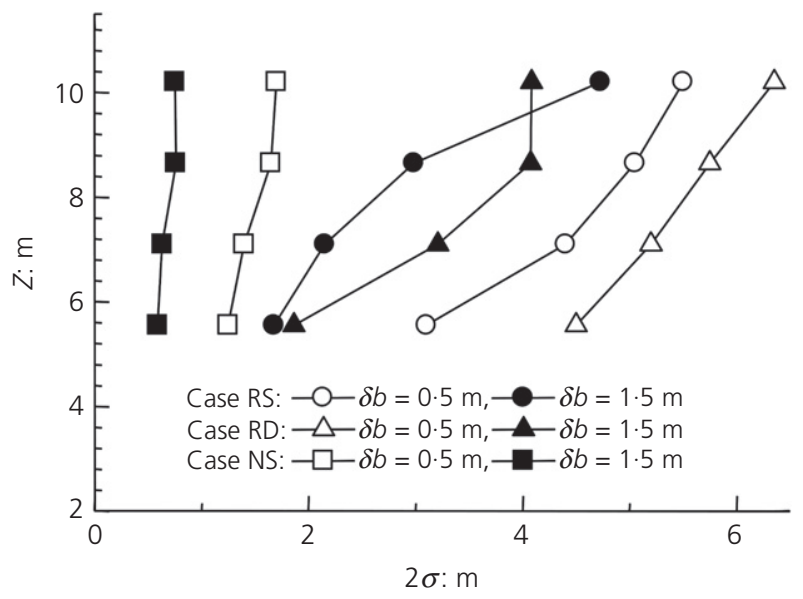

(c)

Figure 10. Approximation of normalised vertical displacement profiles by complimentary error function: (a) an example of evaluation for case RD at $5.6 \mathrm{~m}$ depth when $\delta b=1.0 \mathrm{~m}$; (b) comparison of observed $\delta v / \delta v_{\max }$ and that evaluated by complimentary error function in case RS at different depth when $\delta b=1.0 \mathrm{~m}$; (c) distributions of $2 \sigma s$ along depth in all cases

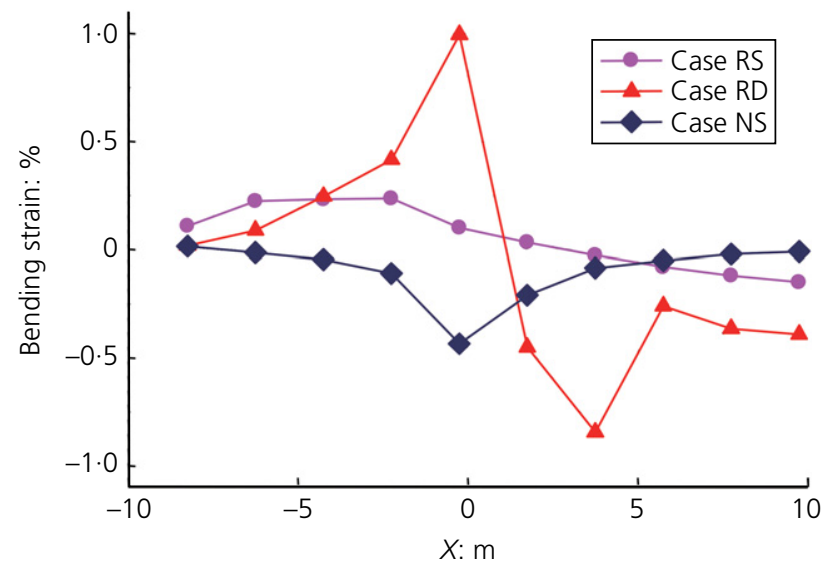

Figure 11. Bending strain of pipes at $\delta b=1.0 \mathrm{~m}$

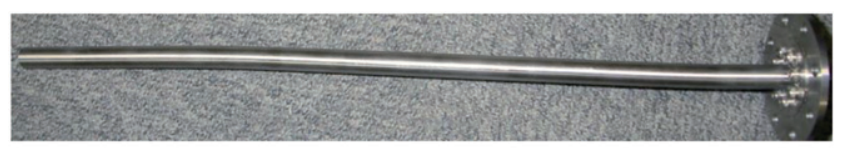

(a)

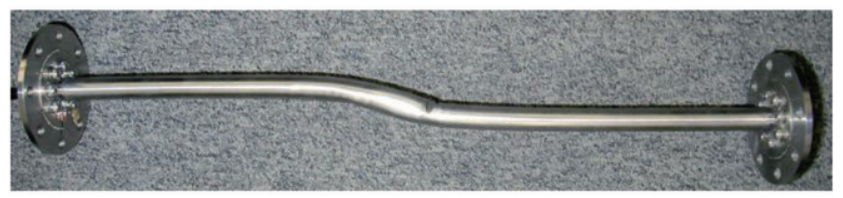

(b)

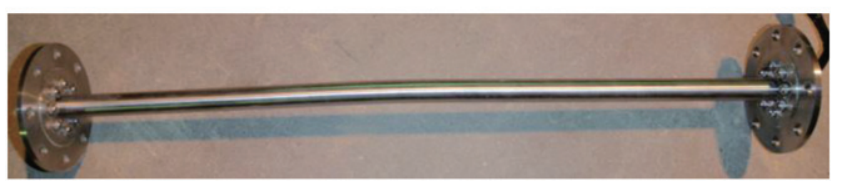

(c)

Figure 12. Deformed pipes captured after tests: (a) case RS; (b) case RD; (c) case NS

positive and negative moments can be seen at both hanging and foot wall sides. The peak locations are close to the location of $x= \pm \sigma$ defined in Figure 9, where the curvature of the vertical displacement profile is the maximum. On the contrary, for case RS, the moment is very small and its maximum was observed outside of the steep differential displacement area (see Figure 8). For case NS, clear positive peak moment was observed at the foot wall side but very close to the rupture, the maximum absolute moment values of case NS is larger than that of case RS.

Deformations of the model pipes observed in each case after the tests are shown in Figure 12 and these observed deformations are compared with the vertical displacements of the ground in 


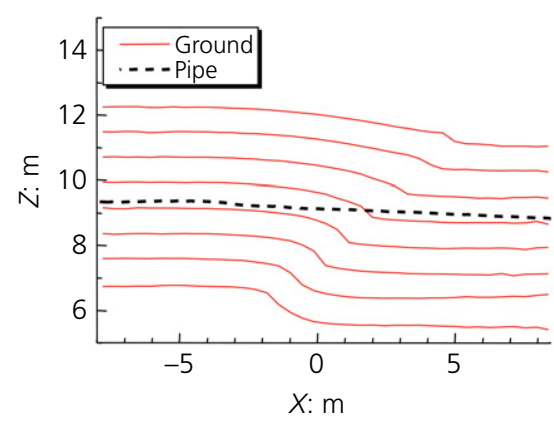

(a)

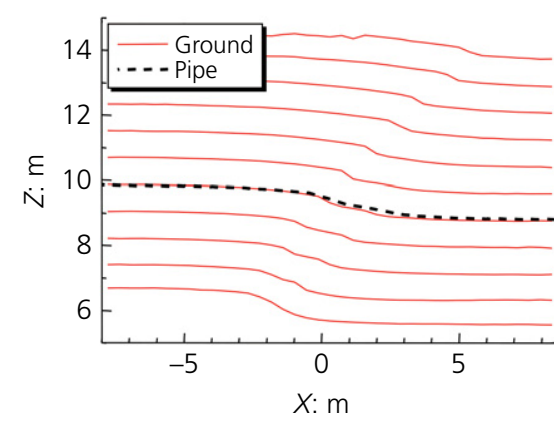

(b)

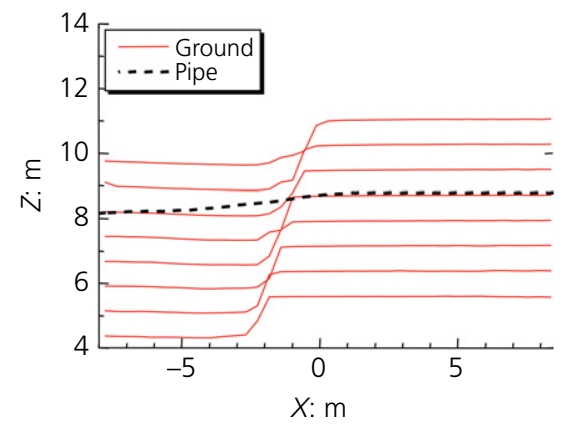

(c)

Figure 13. Deformations of pipes and grounds at $\delta b=1.5 \mathrm{~m}$ : (a) case RS; (b) case RD; (c) case NS

Figure 13. It can be said that the pipe under large confined pressure deformed as the ground did with very small relative displacement between the pipe and ground. In addition, the deformations of the shallow pipes are much less than those of the ground both for the normal and reverse fault. The difference in the behaviour of the deep and shallow buried pipes can be attributed to the relative stiffness of the pipe to the ground. At a shallow depth, increasing the pipe rigidity could be an effective countermeasure against the deformation of alluvium due to the bedrock fault. However, Oliveira et al. (2016) found that the higher the pipe rigidity the higher the stresses developed in the pipe due to soil mass movements. Therefore if the underground structure is constructed at a deep depth, the force from the ground due to faulting is so significant even in an unconsolidated deposit, and rigid and brittle structure may not be a good option for preventing the failure.

\section{Conclusions}

A fault simulator was developed, by which a large overburden pressure can be applied to the model soil to simulate dip-slip fault in a centrifuge. Using the fault simulator, an initial test series on buried pipes are presented. From the test results, the following conclusions were drawn.

(a) The developed fault simulator shows very promising results with respect to rupture propagation, ground deformation and pipe behaviour.

(b) Reverse faulting experienced faster rupture propagate rate and wider rupture zone than normal faulting. In reverse faulting, higher stress level in deeper case resulted in faster propagation and narrower fault zone. For deeper case in reverse faulting, more bedrock offset was required to induce a clear discontinuity.

(c) The complimentary error function is able to approximate the normalised vertical displacement profiles. It provides a simple way to understand the differential settlement zone. (d) Deflection of buried pipes in sand over dip-slip fault is dependent on the relative stiffness of pipe to the surrounding soil. Increasing the pipe rigidity could be an effective measure to reduce the deflection of the shallow buried pipe.

\section{Acknowledgements}

The authors thank Ms. Y. Ishii, a former master's student, and Mr. S. Seki, technician in Geotechnical laboratory in Tokyo Tech, for their contribution to this paper and continuous support during centrifuge tests.

\section{REFERENCES}

Anastasopoulos I and Gazetas G (2007) Foundation-structure systems over a rupturing normal fault: part I. Observations after the Kocaeli 1999 earthquake. Bulletin of Earthquake Engineering 5(3): 253-275.

Anastasopoulos I, Gazetas G, Bransby MF, Davies MCR and El Nahas A (2007) Fault rupture propagation through sand: finite-element analysis and validation through centrifuge experiments. Journal of Geotechnical and Geoenvironmental Engineering 133(8): 943-958.

Baziar MH, Nabizadeh A, Lee CJ and Hung WY (2014) Centrifuge modeling of interaction between reverse faulting and tunnel. Soil Dynamics and Earthquake Engineering 65: 151-164.

Bransby MF, Davies MCR and Nahas AE (2008a) Centrifuge modelling of normal fault-foundation interaction. Bulletin of Earthquake Engineering 6(4): 585-605.

Bransby MF, Davies MCR, El Nahas A and Nagaoka S (2008b) Centrifuge modelling of reverse fault-foundation interaction. Bulletin of Earthquake Engineering 6(4): 607-628.

Bray JD, Seed RB, Cluff LS and Seed HB (1994) Earthquake fault rupture propagation through soil. Journal of Geotechnical Engineering 120(3): 543-561.

Cai QP and Ng CW (2013) Analytical approach for estimating ground deformation profile induced by normal faulting in undrained clay. Canadian Geotechnical Journal 50(4): 413-422.

Cai QP and Ng CW (2014) Effects of the tip depth of a pre-existing fracture on surface fault ruptures in cemented clay. Computers and Geotechnics 56: 181-190. 
International Journal of Physical Modelling in Geotechnics Volume 20 Issue 3
Development of a fault simulator for soils under large vertical stress in a centrifuge

Takemura, Yao and Kusakabe
Chang YY, Lee CJ, Huang WC et al. (2013) Use of centrifuge experiments and discrete element analysis to model the reverse fault slip. International Journal of Civil Engineering 11(2): 79-89.

Chang YY, Lee CJ, Huang WC et al. (2015) Evolution of the surface deformation profile and subsurface distortion zone during reverse faulting through overburden sand. Engineering Geology 184: 52-70.

Chu SS, Lin ML, Huang WC, Liu HC and Chan PC (2013) Laboratoy simulation of shear band development in a growth normal fault. Journal of GeoEngineering 8(1): 19-26.

Cole DA Jr and Lade PV (1984) Influence zones in alluvium over dip-slip faults. Journal of Geotechnical Engineering 110(5): 599-615.

Dash SR and Jain SK (2008) An overview of seismic considerations of buried pipelines. Journal of Structural Engineering 34(5): 349-359.

El Nahas A, Bransby MF and Davies MCR (2006) Interaction between normal fault rupture and rigid strong raft. In Physical Modelling in Geotechnics, Two Volume Set: Proceedings of the Sixth International Conference on Physical Modelling in Geotechnics, 6th ICPMG'06 (Ng CWW, Zhang LM and Wang YH (eds)). CRC Press, Boca Raton, FL, USA, vol. 1, pp. 337-342.

Ha D, Abdoun T, O'Rourke M et al. (2006) Split-containers for centrifuge modeling of permanent ground deformation effects on buried pipeline systems. In Physical Modelling in Geotechnics, Two Volume Set: Proceedings of the Sixth International Conference on Physical Modelling in Geotechnics, 6th ICPMG'06 (Ng CWW, Zhang LM and Wang YH (eds)). CRC Press, Boca Raton, FL, USA, vol. 1, pp. 729-734.

Ha D, Abdoun TH, O'Rourke MJ et al. (2008) Centrifuge modeling of earthquake effects on buried high-density polyethylene (HDPE) pipelines crossing fault zones. Journal of Geotechnical and Geoenvironmental Engineering 134(10): 1501-1515.

Lade PV, Cole DA Jr and Cummings D (1984) Multiple failure surfaces over dip-slip faults. Journal of Geotechnical Engineering 110(5): 616-627.

Lee JW and Hamada M (2005) An experimental study on earthquake fault rupture propagation through a sandy soil deposit. Structural Engineering/Earthquake Engineering 22(1): 1s-13s.

Lee JW, Tabuchi G and Hamada M (2003) Experimental approach for understanding of fault rupture propagation through an alluvial soil. Journal of Earthquake Engineering 27(165): 1-4.

Lin A, Ouchi T, Chen A and Maruyama T (2001) Co-seismic displacements, folding and shortening structures along the Chelungpu surface rupture zone occurred during the 1999 Chi-Chi (Taiwan) earthquake. Tectonophysics 330(3): 225-244.

Lin ML, Chung CF and Jeng FS (2006) Deformation of overburden soil induced by thrust fault slip. Engineering Geology 88(1): 70-89.

Lin ML, Chung CF, Jeng FS and Yao TC (2007) The deformation of overburden soil induced by thrust faulting and its impact on underground tunnels. Engineering Geology 92(3): 110-132.

Miyajima M, Yoshifuji Y and Kitaura M (2003) Experiments on behaviour of buried pipe due to surface fault rupture by using shear soil box. Journal of Earthquake Engineering 27(104): 1-4 (in Japanese).

Ng CW, Cai QP and Hu P (2012) Centrifuge and numerical modeling of normal fault-rupture propagation in clay with and without a preexisting fracture. Journal of Geotechnical and Geoenvironmental Engineering 138(12): 1492-1502.

Oliveira JRM, Rammah KI, Trejo PC, Almeida MS and Almeida MC (2016) Modelling of a pipeline subjected to soil mass movements. International Journal of Physical Modelling in Geotechnics 17(4): 246-256, https://doi.org/10.1680/jphmg.15.00059.
O'Rourke TD and Palmer MC (1996) Earthquake performance of gas transmission pipelines. Earthquake Spectra 12(3): 493-527.

Roboski J and Finno RJ (2006) Distributions of ground movements parallel to deep excavations in clay. Canadian Geotechnical Journal 43(1): 43-58.

Roth WH, Scott RF and Austin I (1981) Centrifuge modeling of fault propagation through alluvial soils. Geophysical Research Letters 8(6): $561-564$.

Sorensen SP and Meyer KJ (2003) Effect of the Denali fault rupture on the trans-Alaska pipeline. In Proceedings of Advancing Mitigation Technologies and Disaster Response for Lifeline Systems. ASCE Technical Council on Lifeline Earthquake Engineering, Long Beach, CA, USA, pp. 547-555.

Stone KJ and Brown TA (1993) Simulation of ground loss in centrifuge model tests. Geotechnical Testing Journal 16(2): 253-258.

Takemura J, Ishii Y and Kusakabe O (2010) Development of a fault simulator in a centrifuge and preliminary study on a buried pipe subjected to a fault differential displacement. In Proceedings of 3rd Asia Conference on Earthquake Engineering, Bankoku, Thailand, CD-ROM.

Tani K, Ueta K and Onizuka N (1994) Scale effects of quantary ground deformation observed in model tests of vertical fault. In Proceedings of 29th Annual Meeting of Japanese Geotechnical Society, Morioka, Japan, pp. 1359-1362 (in Japanese).

Trifunac MD and Todorovska MI (1997) Northridge, California, earthquake of 1994: density of pipe breaks and surface strains. Soil Dynamics and Earthquake Engineering 16(3): 193-207.

Ueta K and Tani K (1999) Deformation of Quaternary Deposits and Ground Surface Caused by Bedrock Fault Movements ( Part 2) Normal and Reverse Fault Model Tests. Central Research Institute of Electric Power Industry, Tokyo, Japan (in Japanese).

Wells DL and Coppersmith KJ (1994) New empirical relationships among magnitude, rupture length, rupture width, rupture area, and surface displacement. Bulletin of the Seismological Society of America 84(4): 974-1002.

White RJ, Stone KJL and Jewel RJ (1994) Effect of particle size on localization development in model tests on sand. Centrifuge $\mathbf{9 4}$ : 817-822.

White DJ, Take WA and Bolton MD (2003) Soil deformation measurement using particle image velocimetry (PIV) and photogrammetry. Géotechnique 53(7): 619-631, https:/doi.org/ 10.1680/geot.2003.53.7.619.

\section{How can you contribute?}

To discuss this paper, please email up to 500 words to the editor at journals@ice.org.uk. Your contribution will be forwarded to the author(s) for a reply and, if considered appropriate by the editorial board, it will be published as discussion in a future issue of the journal.

International Journal of Physical Modelling in Geotechnics relies entirely on contributions from the civil engineering profession (and allied disciplines). Information about how to submit your paper online is available at www. icevirtuallibrary.com/page/authors, where you will also find detailed author guidelines. 